\title{
A GENERATION OF MORE EFFICIENT CNC TOOL PATHS USING SIMULATION MODELLING
}

\author{
Dotcheva, M. \& Millward, H. \\ The National Centre for Product Design and Development Research (PDR), \\ University of Wales Institute Cardiff (UWIC), Cardiff CF5 2YB, UK \\ E-Mail: mdotcheva-pdr@uwic.ac.uk; HMillward-PDR@uwic.ac.uk
}

\begin{abstract}
This paper presents two-phase optimisation strategy for efficient planning of finishing endmilling operations when machining pocket-type features. The optimisation mechanism controls dimensional tolerances through knowledge of cutting forces and the associated cutting tool deflections. The developed model of the end milling process describes the main parameters, such as chip thickness, engagement angles, cutting forces, cutting tool deviation, and simulates the relationship between them during the cutting operation. The created strategy is feed-forward and it is focused on cutting process geometry identification and specifics of machining pocket type features. The model-based simulation covers the general case of endmilling when the chip thickness is variable along the tool path. The developed off-line optimisation methodology creates more efficient milling process with variable feed rate, compared to the same tool path cut with constant feed rate derived from the worst-case condition. Up- and down-milling were modelled and optimised, and the predicted data was evaluated experimentally.

(Received in January 2008, accepted in June 2008. This paper was with the authors 1 month for 1 revision.)
\end{abstract}

Key Words: End-Milling Optimisation, Surface Error, End-Milling Modelling

\section{INTRODUCTION}

End milling is a widely used cutting operation involved in different types of production, such as machining dies and moulds, where the geometry is complex, the tolerances are small and the cost of whole operation is high. Despite tremendous developments in CAM software, cutting-tool technology and machine-tool technology, end-milling results still depend to a large extent on the knowledge inherent within manufacturing staff [1,2]. End-milling machining is a complex process in terms of process planning due to intricate geometry, the evolution of new materials and high-precision requirements of the final product. Consequently, the full potential of the machine tool system is under utilised in many cases. CAD/CAM systems can generate CNC programs based on the part geometry, but they do not help programmers to choose appropriate cutting conditions and other process parameters, such as step over, cutting direction, cutter entrance and exit, and type of transition between the strokes of the tool path. Commercial CAM products develop the CNC programmes mainly from the mathematical point of view and usually the feed rate and spindle speed are constant for a given tool path, derived from the worst-case cutting condition. Consequently, the machining practice in the majority of cases of end-milling operations is conservative and the planned cutting processes are not optimal [3, 4, 5].

The CNC code generation/verification performed by available CAD/CAM systems is limited to checking nominal geometric dimensions. The primary goal of the existing commercial simulation and verification products is to detect and to prevent the collisions and other errors before the programme is loaded on the machine tool, and to eliminate the time- 
consuming manual prove-out cycle. However, they do not simulate the expected accuracy of the machined surfaces, and hence they do not optimise the cutting conditions $[6,7,8]$.

The available commercial CAD/CAM systems also fail to take into account the mechanical aspects of the milling process. The mechanical parameters such as cutting forces and cutting-tool deviation are important for an evaluation of process capabilities and machining results. Excessive cutting forces can lead to breakage of the cutting tool, damage of the machine tool and production scrap, and hence an inability to leave the working machine tool unattended. As [9] state, in the real machining process there are some disturbance factors such as cutter and part deflection, and runout, which are important for the milling operation and are not incorporated in commercial CAD/CAM systems. The realistic prediction of the mechanistic parameters requires a model-based simulation environment which can model the milling operation, applying different process requirements. Consequently, a practicallyorientated simulation and optimisation methodology, with clear intent and strategy, can be a tool for achieving better machining results. An advantage of this simulation format is that it is a feed-forward process and does not take up valuable machine time. By employing multiple models, the simulation technique can rapidly predict, control and optimise the whole machining process.

The work described in this paper is built on previous research and is intended for finishing end-milling operation. The basis of the developed optimisation methodology is the endmilling model. End-milling is placed in context by firstly considering tolerance analysis of the whole process, and then focusing on the application for corner cutting. The key parameters are identified in terms of the relationship between the cutting forces and radial cutting-tool deflection. A mathematical model forms the basis for an optimisation strategy judged in terms of a combination of surface accuracy, surface roughness and machining (finishing) time. The implementation methodology for machining a pocket type feature is presented.

\section{OPTIMISATION STRATEGY}

This research work presents a strategy to optimise the feed rate for an end-milling finishing operation. The optimisation procedure maintains 'in tolerance' end-milling accuracy, whilst reducing machining time and controlling surface roughness. 'In tolerance' accuracy means that after optimisation of a given milling operation, the error of the machined surface will be within limits of the design tolerance. Furthermore, the proposed strategy increases the feed rate to the allowable level in increments to make the process more time efficient - not just accurate. The main constraint for defining the maximum allowable feed rate is surface tolerance accuracy.

Fig. 1 presents the flowchart of the developed model-based optimisation process. It was assumed that the cutting tools, the machine tool, the part's geometry and design requirements had been defined. The tool-path planning for a single end-milling operation is made in the available CAD/CAM system. The generated tool path has preliminary constant cutting conditions for the whole contour. This constant feed rate is taken from the reference books or is based on the previous experience. Then the two phases of the optimisation process follow. In the first phase, the constant feed rate $\left(f_{\text {con }}\right)$ is derived from the worst-case milling condition, whereby peak chip thickness for a given tool path generates the maximum tool loading. For this worst-case condition, an analysis of the errors of the milling process is performed. The aim of this analysis is to obtain the limiting radial deviation of the cutter $\left(\delta_{\text {lim }}\right)$ taking into consideration the surface tolerance requirement and the process errors. The radial deviation of the cutting-tool is the deviation component obtained in radial direction towards the machined surface. Another constraint which is included in the optimisation process for feed rate calculation is the surface roughness. The limiting radial deviation of the cutter defines the 
maximum allowable cutting force $\left(F_{\max }\right)$ and the constant feed rate $\left(f_{\text {con }}\right)$ for achieving the required surface roughness and accuracy. Employing the model of the end-milling process, the cutting forces and the deviation of the cutting-tool are calculated at each incremental cutter position using the constant feed-rate condition. If the optimisation strategy ends with the phase one, the end-milling process will be accurate but not efficient.

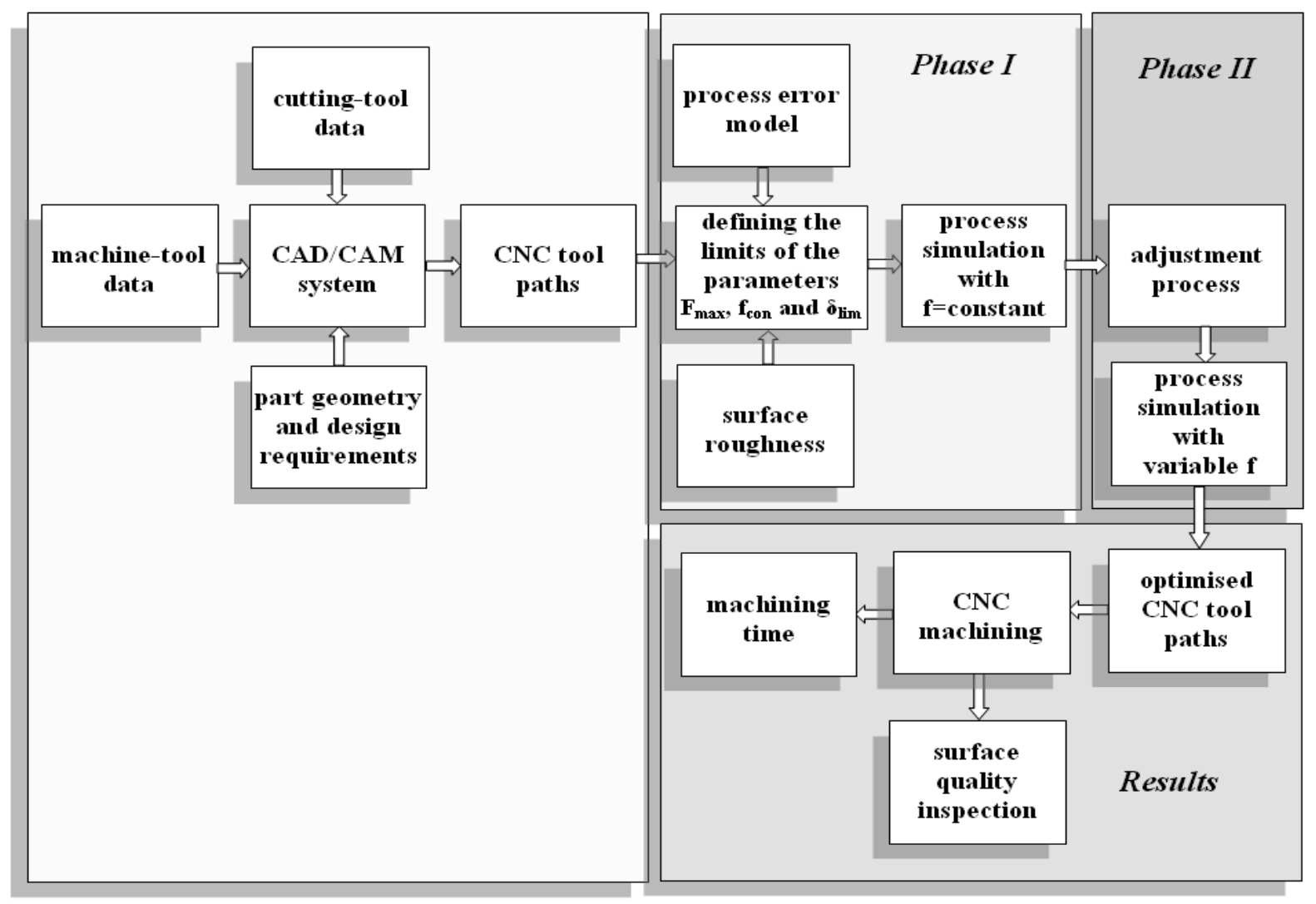

Figure 1: Flowchart of the optimisation strategy.

An example of corner cutting is given in Fig. 2. The worst-case condition is at the beginning of the corner where the chip thickness is at its peak value. If the constant feed rate defined from this worst-case condition is applied to the whole tool path, the accuracy will be higher than that required for the greater part of the machined contour.

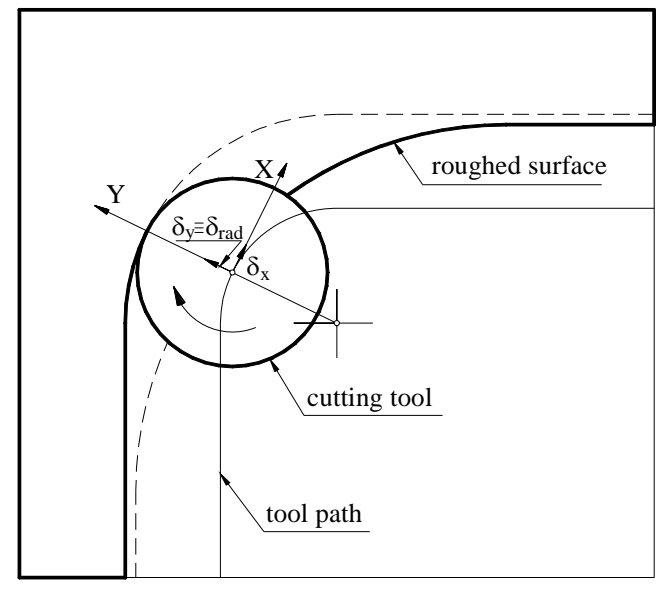

Figure 2: Corner cutting and the deviation components of the cutting-tool, during corner end milling. 
The important rule in manufacturing is not to generate a process with a higher degree of accuracy than is required. The machining time of the milling with constant cutting conditions will be long, and the cutting process is sub-optimal. Therefore there is a need for a second phase within the proposed optimisation strategy.

The second phase (Fig. 1) of the optimisation strategy uses the data from phase one, with the aim of generating optimised cutting conditions for the whole tool path. To apply the feedrate adjustment mechanism, the limit of the cutter deviation defined in phase one is used. After synthesising the predicted radial cutter deviation and surface roughness based on the cutting forces, they are compared with the required values. If the two constraints are not satisfied, the feed rate is adjusted to reach the designed surface tolerance and surface roughness. The result from this stage is a variable feed rate corresponding with the tool path data for a given surface. The final stage takes the new optimised feed rate and, through the appropriate CAD/CAM software, translates this into the cutter location (CL) file for the CNC machine tool.

\subsection{Process modelling and simulation}

All predicted and optimised parameters in the optimisation process are obtained using the developed hybrid model of the end-milling operation shown in Fig. 3. For the general case, it is assumed that the cutting-tool, machine tool and machining process are determined, and the dimensional accuracy and surface roughness are specified.

This model is applied in both phases of the optimisation mechanism (shown in Fig. 1):

1. Preliminary calculations with constant feed rate;

2. Simulation of the optimised milling process.

The process simulation module is a complex process, which integrates different models, such as chip-thickness model, cutting-force model, cutting-tool deviation, and cutting-force coefficients definition. The key parameters of the end-milling modelling are the cutting forces $[5,10,11]$, which are proportional to the analytically-defined chip thickness. The chip thickness is a very important parameter in any force model, and a special module has been developed in this work for its accurate calculation. The chip-thickness size is considered as a variable and it has been defined for every important cutter location along the tool path, taking into account the part geometry, the cutting-tool parameters, the geometry of the previous milling operation and the feed rate. Through the chip-thickness and cutting-force models, the specifics of up- and down-milling are taken into consideration in the developed optimisation strategy. A special module which defines the cutting-force coefficients [12] is included in the end-milling simulation because these coefficients depend on the part and cutting-tool material, and on the cutting process geometry. As the cutting-tool deviation reflects the action of the cutting forces and is the main parameter in machining error equation, it takes the major part in the simulation and optimisation process. To assess the operation performance and to predict the surface machining error, this study employs a static model to calculate the deviation of the cutting-tool. The model does not take into consideration the deflection of the machine tool, cutting-tool holder and test part's deformation; it is assumed that these deflections are minor in comparison to the cutting-tool deflection. Each module from the endmilling model can be used independently for the simulation of different process parameters.

\subsection{Machining error consideration.}

The main constrain in the optimisation strategy is the surface accuracy. To predict the surface error of the machined features, an analysis of the errors that occur in the milling process has to be performed. The main sources of errors during the milling operation are:

1. Geometrical error of the machine tools. 


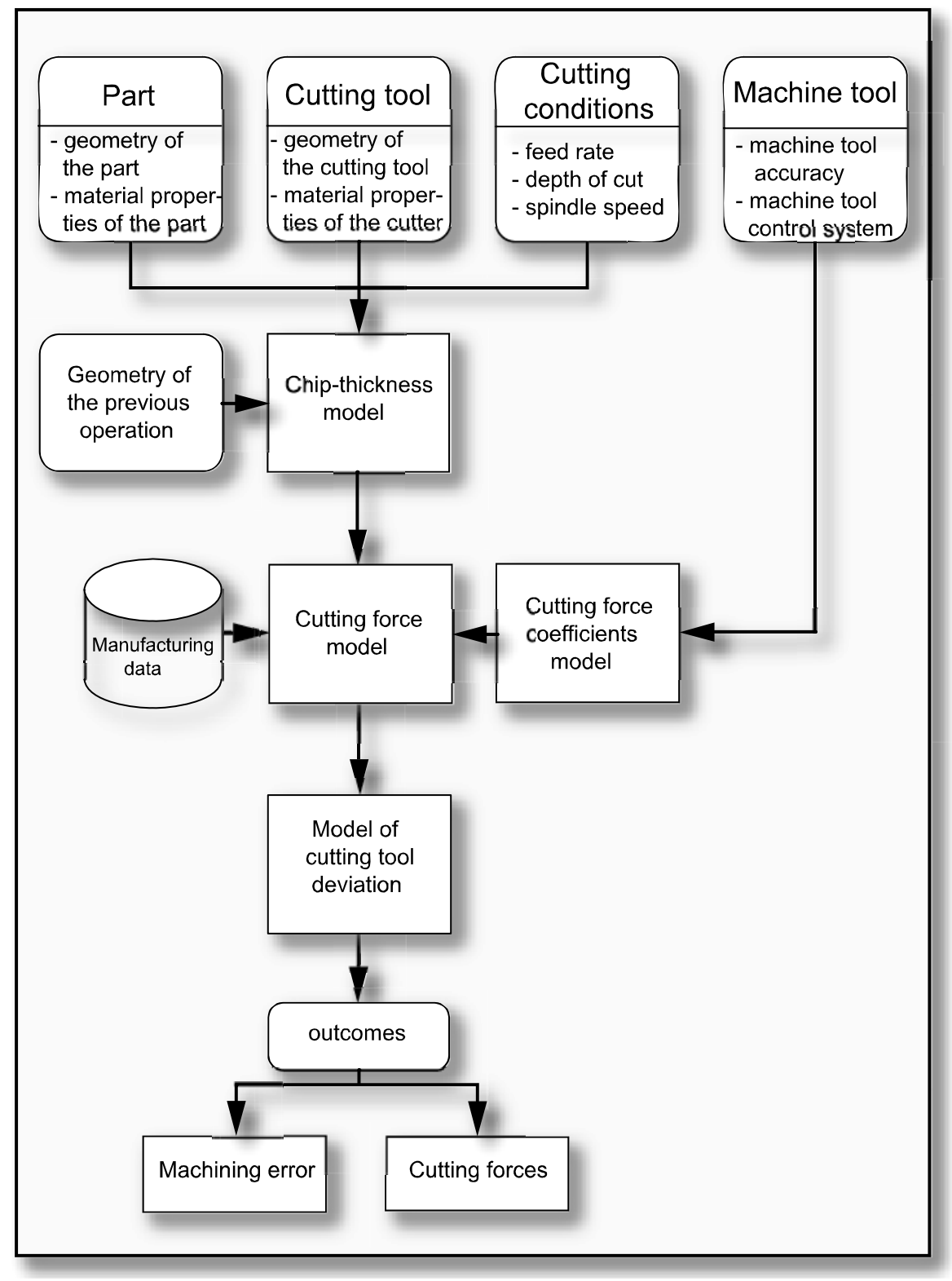

Figure 3: End-milling process model.

2. Error from the part set-up and clamping. In this research work two different cutting conditions were cut on the same set-up in order to reduce the influence of the fixing error.

3. Errors from cutting-tool placement, wear and inaccuracy.

4. Error from deformations in machine tool/cutting tool/work piece system. In end-milling, the cutting-tool is the significant element that is deformed under cutting forces; hence, the main focus of this research is the estimation of cutting forces and the resulting cutting-tool deflection.

5. Error from temperature deformation in machine tool/cutting tool/work piece system and error from residual deformations in the work piece. It is not possible to eliminate or to avoid them, and in this work they are typically referred to as additional errors.

The parameter that is used for defining the optimum feed rate for a given process is the limiting radial deviation $\left(\delta_{\text {lim }}\right)$. The radial cutter deviation is illustrated in Fig. 2 . In the straight segment of the tool path the radial deviation coincides with the deviation of the cutting-tool in the $Y$ direction. Defining the radial deviation in corner cutting depends on the local co-ordinate system that is introduced. In the case shown in Fig. 2, the $Y$-axis is always 
in the radial direction to the machined surface, and the tolerance of the surface has to be defined directly by the maximum deviation in $Y$. When the local co-ordinate system does not change the direction of its axes while the cutting-tool is moving along the tool path, the radial deviation does not coincide with deviation in $X$ or $Y$. The simulation process covers both these cases for defining the radial cutter deviation.

The limiting radial deviation of the cutting-tool is derived by taking into account the required surface tolerance $\left( \pm \Delta_{\text {total }}\right)$, the machine tool geometric errors $\left(\Delta_{m t}\right)$, the tolerance of generating the tool path $\left(\Delta_{t p}\right)$, the tolerance of the diameter of the cutting-tool $\left(\Delta_{c t}\right)$, and the additional cutting process errors $\left(\Delta_{a d d}\right)$. The key relation between these parameters is given below:

$$
\Delta_{\text {total }}=\left|\delta_{\text {lim }}\right|+\left|\Delta_{t p}\right|+\left|\Delta_{c t}\right|+\left|\Delta_{m t}\right|+\left|\Delta_{a d d}\right|
$$

The new optimised feed rate $\left(f_{\text {opt }}\right)$ is then obtained using the limiting radial cutting-tool deviation $\left(\delta_{\text {lim }}\right)$, the maximum radial deviation $\left(\delta_{\text {rad }}\left(f_{\text {con }}\right)\right)$ at every important tool location $\left(X_{c}, Y_{c}\right)$ and the constant feed rate $\left(f_{\text {con }}\right)$ :

$$
f_{\text {opt }}\left(X_{c}, Y_{c}\right)=f_{\text {con }} \frac{\delta_{\text {lim }}}{\delta_{\text {rad }}\left(f_{\text {con }}\right)}
$$

The optimised feed rate is solved for a rotation angle of $0^{\circ}$ to $360^{\circ}$ in one-degree increments for each cutter position. In addition to dimensional accuracy, a surface roughness constraint is also applied during the optimisation process. The maximum predicted surface roughness is maintained with the limits as defined by the simple model proposed by [13]:

$$
R_{a}=\sqrt{\frac{f_{t} \sqrt{2 R_{i}}}{0.6 N_{f}}}
$$

where $R_{a}$ is a surface roughness parameter giving the arithmetical mean deviation of the machined profile, $f_{t}$ is feed rate per tooth (mm/tooth), $R_{i}$ is cutting tool radius (mm), $N_{f}$ is number of the cutting tool's teeth.

The above surface roughness equation is for down-milling. To obtain the same surface roughness with up-milling the feed rate has to be 6-12 \% larger than that in down-milling [13]. For this study, it is applied to the straight segments of the tool path where the feed rate is at its highest. Furthermore, the machining simulation needs to ensure that the feed rate is within the machine tool's limits, and that the lengths of the CAM arc increments are within the allowable tolerance for generating the tool path.

\section{IMPLEMENTATION OF THE OPTIMISATION STRATEGY}

\subsection{The machining case}

A pocket is a closed or an open feature with walls that can have different shapes and rounded corners. Generally pockets are considered as complex part elements, with variable machining geometry. Pockets are roughed first, and then a finishing operation is performed for obtaining the final surface accuracy. The main factors that affect machining time in pocket manufacture are tool diameter, tool paths and cutting conditions. The diameters of the cutters for the roughing and finishing operations are defined by different criteria, such as pocket geometry, cutting-tool wear, surface requirements, and machining time. In this research work the diameters of roughing and finishing cutters are chosen in order to create a general example of corner milling. The general case for corner cutting is when the diameter of the roughing cutter 
is larger than the diameter of the finished part corner. In this instance at the corner, the finishing cutter is moving along an arc tool path segment, because of the difference between the radii of the two cutters. This general case is shown in Fig. 4.

During contour milling, the uncut chip thickness depends on the position of the cuttingtool, tool path, cutting-tool diameter $R_{i}$, geometry of the previous operation and final part geometry. In straight tool path segments, the chip thickness is constant and relatively easy to calculate. However, the chip thickness continuously varies during the radial corner segment.

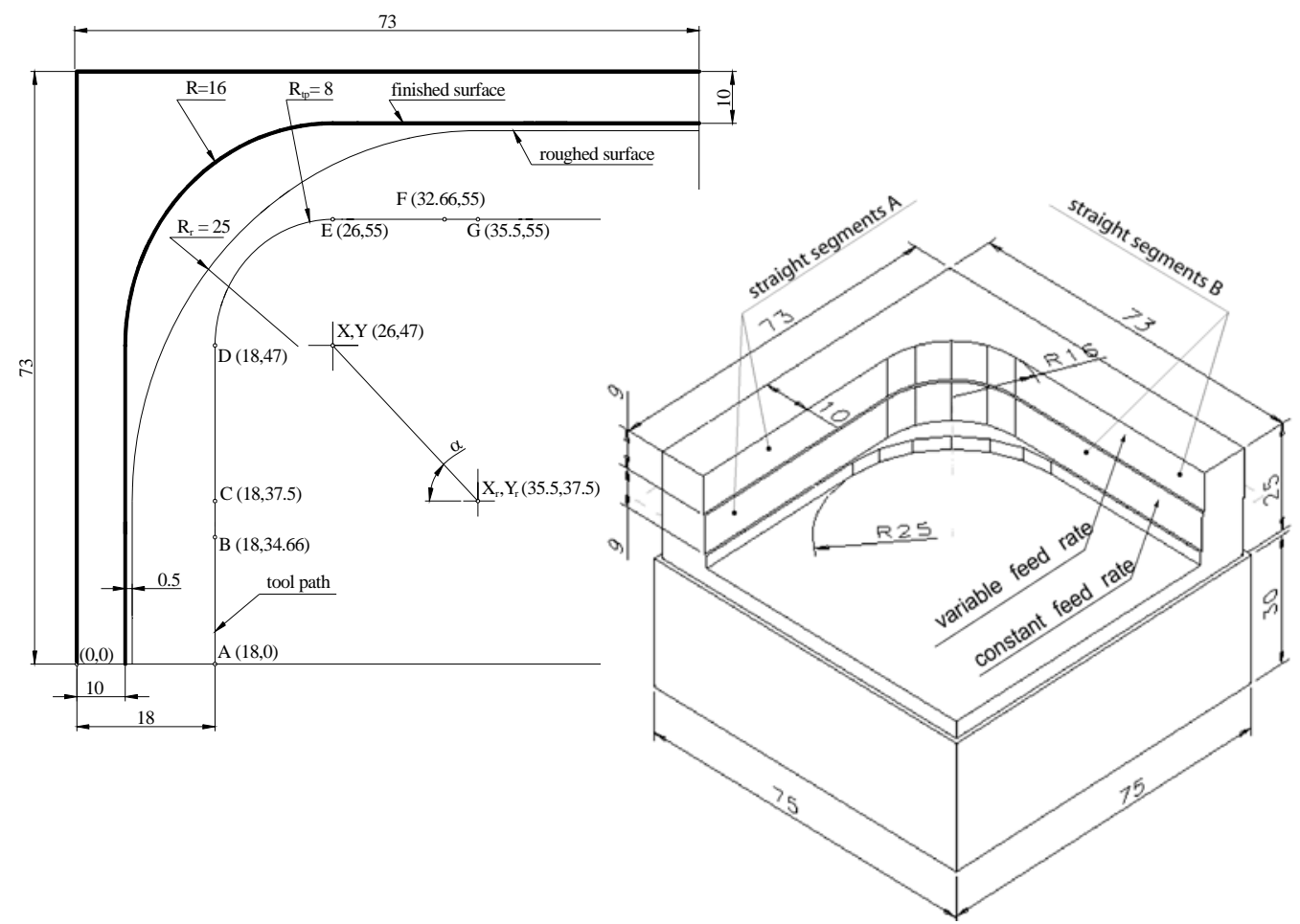

Figure 4: The general case of corner milling.

From point A to point B of the tool path, the cutter performs steady straight-line cutting. The radial depth of cut in this part of the tool path is constant. The cutting condition from point $\mathrm{B}$ to point $\mathrm{D}$ represents the transient from straight segment to corner entry. In the B-D part of the tool's trajectory, the cutter still moves along a straight tool path but because of the larger diameter of the roughed part surface, the chip thickness and the whole cutting process are variable. At the beginning of this segment, the chip thickness is equal to the constant chip thickness and at the point $\mathrm{D}$ it reaches the maximum value.

The corner milling starts at point $\mathrm{D}$ and it finishes at point E. From location $\mathrm{D}$ to $\mathrm{E}$, the centre point of the cutter is moving along a circular tool path with radius $R_{t p}$. The chip thickness constantly varies during corner milling, and consequently influences the whole machining process.

\subsection{Corner optimisation}

The tolerance analysis and corner-cutting geometry analysis have been applied to a pockettype test piece, and the inside corner geometry is shown in Fig. 4. The roughing radius was set at $25 \mathrm{~mm}$ and the finished inside-corner radius at $16 \mathrm{~mm}$. The difference between the radius of the roughing cutter and the radius of the finished corner creates a cutting geometry with variable chip thickness. The test piece was designed to incorporate two identical surfaces, which allows the paired-comparison experiment to be implemented. The two controlled surfaces of a test piece were cut with different cutting conditions. The first cutting condition 
was derived from the worst-case peak-chip-thickness along the whole tool path. The second cutting condition was obtained after applying the optimisation strategy to the same contour with variable geometry.

The allowable deviation of the cutting tool under the cutting forces was calculated to be $\delta_{\text {lim }}= \pm 0.03 \mathrm{~mm}$. The $\delta_{\text {lim }}$ value was employed to limit the predicted cutting tool deviation, and the first step in the optimisation process was to derive the worst-case constant-feed-rate condition that generates this value. For the given geometry, the maximum chip thickness condition occurs after a tool-path travel distance of $47 \mathrm{~mm}$, as shown in Fig. 5. The analysis of the geometry presented in Fig. 5 follows the movement of the cutter and calculates the engagement angle. The largest engagement angle defines the worst-case condition for the contour given in Fig. 4. From the engagement angle analysis it is clear that the feed-rate adjustment process, in order to maintain a constant surface accuracy at the highest possible cutting speed, has to start long before the start point of the corner.

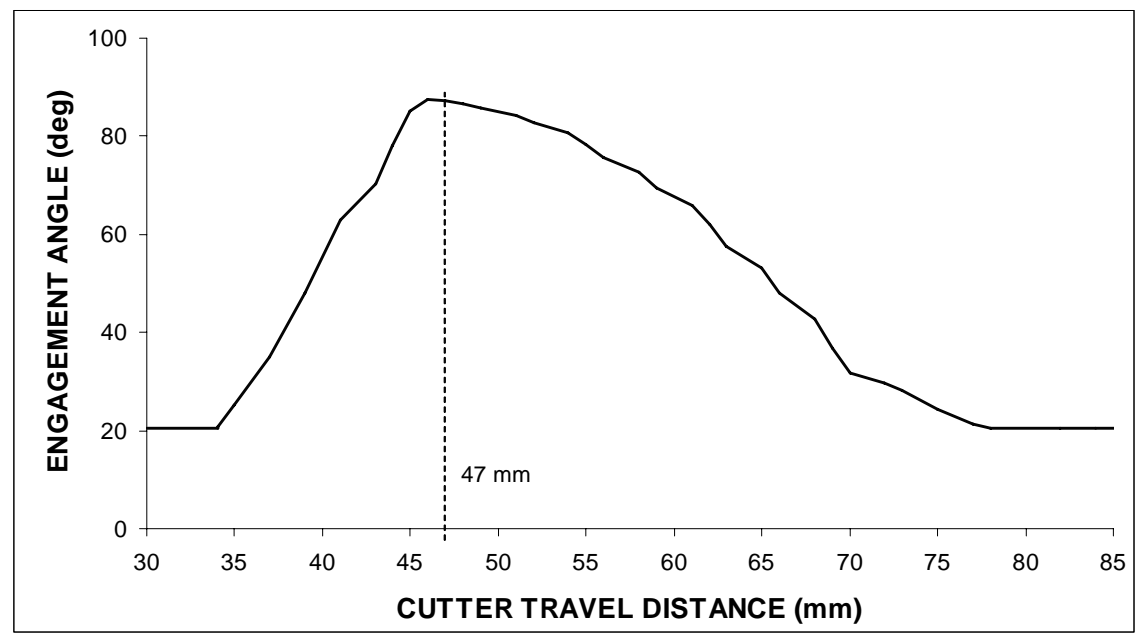

Figure 5: The variable engagement angle when cutting along the tool path shown in Fig. 4.

After identifying the worst-case condition for the given tool path, the cantilever-based force model was employed to give a constant feed-rate condition. Then the optimisation of the feed rate was performed.

The two contrasting feed rates are shown together, with respect to cutting tool travel distance, in Fig. 6. The optimised feed-rate decelerates to the constant feed-rate value at the point of peak chip thickness (i.e. the start of the corner), and then accelerates back to a maximum according to the chip load at every cutter position. In the straight part of the pocket the chip load does not change and the optimised feed rate is constant. The feed rate in the straight segment is lower than the maximum allowable from the cutting tool deviation condition because of the limitation of the surface roughness criterion, which was set by the arithmetical mean deviation of the profile to be $R_{a}=0.8 \mu \mathrm{m}$. The transient cutting conditions prior to the point of maximum chip thickness reduces the feed rate before the corner, which limits tool loading and creates an overall smoother milling process. At the end of the corner, the chip thickness becomes constant and equal to the chip thickness at the straight part of the pocket, and the feed rate obtains the highest allowable rate.

The constant feed rate for up-milling is $f=0.048 \mathrm{mmpr}$, whilst for down-milling it is $f=$ $0.036 \mathrm{mmpr}$. The difference is due to the larger radial cutting force in down-milling, which induces a larger cutter deviation. Fig. 6 shows the comparison between the constant and variable feed rate in up- and down-milling. The variable feed rate, which is a result of the optimisation process, is larger in up-milling than the variable feed rate in down-milling for the whole cutting process. This optimised feed rate for the milling operation determines shorter 
machining time when up-milling is employed. The optimisation process of up-milling generates higher levels of the feed rate than the same process applied to down-milling. The higher feed rate determines shorter machining time, which means that the up-milling optimised process is expected to be more efficient than the optimised down-milling, whilst maintaining the same surface accuracy and surface roughness.

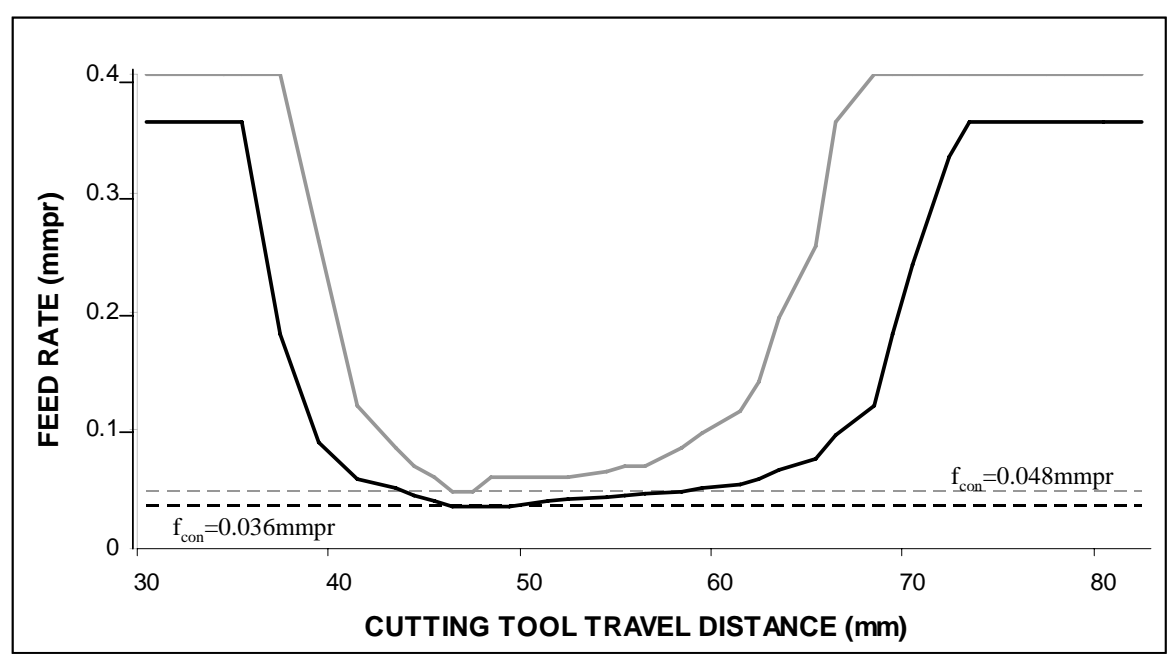

Figure 6: Constant and variable feed rate in up-milling shown in grey colour, and in downmilling drawn in black colour.

After generating the new feed-rate data for up- and down-milling, two test pieces were machined applying the new cutting conditions. The test pieces were cut on a Mikron HSM 400. The geometry of the parts is the same as shown in Fig. 4. The experimental data used in the machining experiments is given in Table I.

Table I: The experimental data for the cutting processes.

\begin{tabular}{|l|l|}
\hline Cutting tool: & $16 \mathrm{~mm}$ HSS 3 fluted with $30^{\circ}$ helix angle \\
\hline Cutting tool rake angle: & $7^{\circ}$ \\
\hline Cutter overall length: & $77 \mathrm{~mm}$ \\
\hline Cutter effective length: & $50 \mathrm{~mm}$ \\
\hline Flute length: & $30 \mathrm{~mm}$ \\
\hline Cutting-tool material: & High Speed Steel (HSS) \\
\hline Modulus of elasticity: & $200 \mathrm{GN} / \mathrm{m}^{2}$ for HSS (Ashby and Jones 1996) \\
\hline Test-piece material: & Aluminium alloy 6082 \\
\hline Cutting-force coefficients: & $K_{T}=1292 \cdot t_{c}^{-0.1657}, K_{R}=0,4477 \cdot t_{c}^{-0.01307}$ \\
\hline Machine tool: & Mikron HSM 400 \\
\hline
\end{tabular}

The results from the test pieces cut with up- and down-milling using the constant and optimised cutting conditions are summarised in Table II. The surface error comparison shows that up-milling provides better accuracy with both cutting conditions. The maximum surface error in down-milling is significant due to the specifics of this type of milling. The surface roughness results do not exceed the required surface roughness $R_{a}=0.80 \mu \mathrm{m}$. The surface roughness in down-milling is higher than the same parameter in up-milling even though the feed rate in up-milling is larger than the feed rate used in down-milling. The constant feedrate condition creates lower roughness than the surface roughness of the strips cut with optimised feed-rate conditions. In both types of milling the operations cut with optimised feed-rate are more efficient than the operations with constant feed rate. For up-milling, the 
machining time of the optimised tool path is $78 \%$ shorter than the machining time of the operation with constant feed rate. In down-milling the machining time of the optimised operation is $74 \%$ of the machining time with constant feed-rate cutting. The considerable difference between the machining time of the operations with variable and constant feed-rate comes from the geometry of the finishing operation. This geometry was deliberately designed to create extreme cutting conditions.

Table II: Summary of key machining measurements for the optimised and constant feed-rate conditions (magnitude values of the surface error are given).

\begin{tabular}{|l|c|c|c|c|}
\hline & \multicolumn{2}{|c|}{ Up-milling } & \multicolumn{2}{c|}{ Down-milling } \\
\cline { 2 - 5 } & $\begin{array}{c}\text { Constant } \\
\text { Feed Rate }\end{array}$ & $\begin{array}{c}\text { Optimised } \\
\text { Feed Rate }\end{array}$ & $\begin{array}{c}\text { Constant } \\
\text { Feed Rate }\end{array}$ & $\begin{array}{c}\text { Optimised } \\
\text { Feed Rate }\end{array}$ \\
\hline $\begin{array}{l}\text { Maximum Measured } \\
\text { Surface Error }(\mathrm{mm})\end{array}$ & 0.0193 & 0.0362 & 0.0496 & 0.0562 \\
\hline $\begin{array}{l}\text { Measured Surface } \\
\text { Roughness } \mathbf{R}_{\mathrm{a}}(\mu \mathrm{m})\end{array}$ & 0.213 & 0.400 & 0.280 & 0.712 \\
\hline Finishing Time $( \pm 1 \mathrm{~s})(\mathrm{s})$ & 55 & 12 & 97 & 25 \\
\hline
\end{tabular}

The machining time depends on the feed rate employed in the cutting process when other cutting parameters are the same. It has been expected that up-milling operations will provide shorter machining time because of the higher values of the feed rate in both cases of cutting when constant and variable feed rate are applied (Fig. 6). The experimental results confirm the predicted trend. Comparing the finishing machining times, up-milling is $40 \%$ more efficient than down-milling

\section{CONCLUSION}

This paper presents a simulation-based optimisation strategy for efficient planning of finishing end-milling operations. The optimisation strategy incorporates the design tolerance into an error stack that relates directly to the CAD/CAM output. The machining optimisation strategy was focused on one critical machining parameter: the limiting radial cutting-tool deviation. As the cutting-tool deviation reflected the action of the cutting forces and was the main parameter in the machining error equation, the end-milling model took a major part in the process simulation and optimisation process. The optimised feed rate is obtained as the milling process is simulated at the highest possible speed whilst maintaining the required surface tolerance and surface roughness. The developed off-line optimisation methodology creates a more efficient milling process with variable feed rate, compared to the cutting of the same tool path with constant feed rate derived from the worst-case condition. This conclusion can be made even before the experimental verification, because the obtained values of the variable feed-rate for the most of the tool path are higher than the defined constant feed-rate, which means faster machining.

The experimental results validated the theoretically developed optimisation strategy. With the new optimised feed rates an enhancement in productivity is achieved. They verify the assumptions and models used for developing the optimisation strategy. The particular case of the inside-corner tool path has been addressed. The corner-cutting model and geometry employed in this research work cover a variety of realistic cutting conditions, which can be found in a range of end-milling profiles. The model presented here is capable of defining the cutter engagement under various cutting conditions. By taking into consideration the required surface tolerance, the geometrical error of a specific machine tool, the accuracy of the cutting 
tool and the tolerance of the generated CAD/CAM tool path, this general optimisation approach can be transferred to any end-milling operation.

Two different types of end-milling were tested. Up-milling demonstrates better results than down-milling in terms of process efficiency, surface accuracy and surface roughness. The evaluation of the two types of milling, based on the simulation data and on experimental results show that up-milling is the more efficient method for finishing end-milling.

The optimisation strategy and the performed experiments confirmed the findings of previous research [14] that reported the experimentally defined cutting speed for various work-piece materials is four to eight times larger than the one recommended by the cutter manufacture. The predicted and the experimental results presented in the paper demonstrate the need for a wider use of end-milling optimisation that takes into consideration the work piece material, the tool-path geometry, the design tolerances and the cutting-tool specification, otherwise worst-case feed-rate settings will predominate.

\section{REFERENCES}

[1] Stori, J. A.; Wright, P. K.; King, C. (1999). Integration of process simulation in machining parameter optimization, ASME Journal of Manufacturing Science and Engineering, Vol. 121, No. 1, 134-143

[2] Li, Z. Z.; Zheng, M.; Zheng, L.; Wu, Z. J.; Liu, D. C. (2003). A solid model-based milling process simulation and optimization system integrated with CAD/CAM, Journal of Materials Processing Technology, Vol. 138, 513-517, doi:10.1016/S0924-0136(03)00137-7

[3] Fussell, B. K.; Jerard, R. B.; Hemmett, J. G. (2001). Robust feed-rate selection for 3-axis machining using discrete models, ASME Journal of Manufacturing Science and Engineering, Vol. 123, No. 2, 214-224

[4] Jawahir, I. S.; Balaji, A. K.; Rouch, K. E.; Baker, J. R. (2003). Towards integration of hybrid models for optimized machining performance in intelligent manufacturing systems, Journal of Materials Processing Technology, Vol. 139, 488-498, doi:10.1016/S0924-0136(03)00525-9

[5] Ko, J. H.; Cho, D. W.; Ko, T. J. (2003). Off-line feed rate scheduling for 3D ball-end milling using a mechanistic cutting force model, Transactions of NAMRI/SME, Vol. 31, 113-120

[6] Schmitz, T.; Ziegert, J. (1998). Premachining CNC contour validation, Precision Engineering, Vol. 22, No. 1, 10-18, doi:10.1016/S0141-6359(97)00086-X

[7] Spence, A. D.; Abrari, F.; Elbestawi, M. A. (1999). Integrated solid modeller based solutions for machining, Fifth Symposium on Solid Modelling, Ann Arbor, USA, 296-305

[8] Bouzakis, K. D.; Aichouh, P.; Efstathiou, K. (2003). Determination of the chip geometry, cutting force and roughness in free form surfaces finishing milling, with ball end tools, International Journal of Machine Tools and Manufacture, Vol. 43, 499-514, doi:10.1016/S02578972(03)00587-5

[9] Cho, M. W.; Seo, T. I. (2002). Machining error compensation using radial basis function network based on CAD/CAM/CAI integration concept, International Journal of Production Research, Vol. 40, 2159-2174

[10] Kline, W. A.; DeVor, R. E.; Lingberg, J. R. (1982). The prediction of cutting forces in end milling with application to cornering cuts, International Journal of Machine Tools and Design Research, Vol. 22, 7-22, doi:10.1016/0020-7357(82)90016-6

[11] Fu, H. J.; DeVor, R. E.; Kapoor, S. G. (1984). A Mechanistic model for the prediction of the force system in face milling operations, Journal of Engineering for Industry, Vol. 106, 81-88

[12] Dotcheva, M.; Millward, H.; Lewis, A. (2008). The evaluation of cutting-force coefficients using surface error measurements, Journal of Materials Processing Technology, Vol. 196, 42-51, doi:10.1016/j.jmatprotec.2007.04.136

[13] Halevi, G.; Weill, R. D. (1995). Principles of Process Planning, A Logical Approach, Chapman \& Hall, London

[14] Paris, H.; Delhez, C. (2000). Modelling cutting force in high speed milling, CIRP II International Seminar on Improving Machine Tool Performance, La Baule, France 